\section{P-BR-079}

BASIC RESEARCH

\title{
Type $\mathrm{H}$ blood, do they influence bone regeneration guided by bone substitutes?
}

\section{Marger L., Schaub L., Strasding M., Sailer I. and Durual S.}

Division of fixed prosthodontics and biomaterials,

Laboratory of Biomaterials,

UNIVERSITÉ

University clinic of dental medicine,

DE GENÈVE

University of Geneva.

FACULTÉ DE MÉDECINE

Clinique universitaire de

\section{Abstract}

During the bone regeneration process, endothelial $\mathrm{H}$ vessels maintain osteoprogenitors niches. In a calvarial bone regeneration model, we aim to determine the relative presence of endothelial $\mathrm{H}$ cells-osteoprogenitors niches depending on bone substitutes of various composition and porosity.

Rabbit calvarial model for vertical bone augmentation (JoVE. 2019 Aug 13;(150). doi: 10.3791/59976)

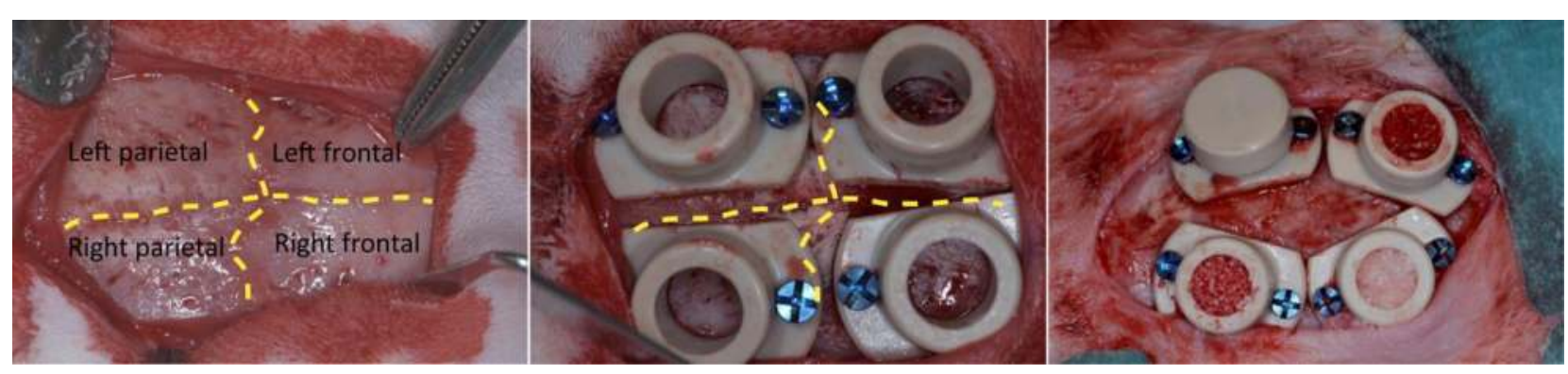

New Bone growth evaluation 2-4 wks, (a-b) Masson Goldner staining; (c-d) Semiquantitative evaluation (digital processing, bone substitute extraction) 2 wks 4 wks

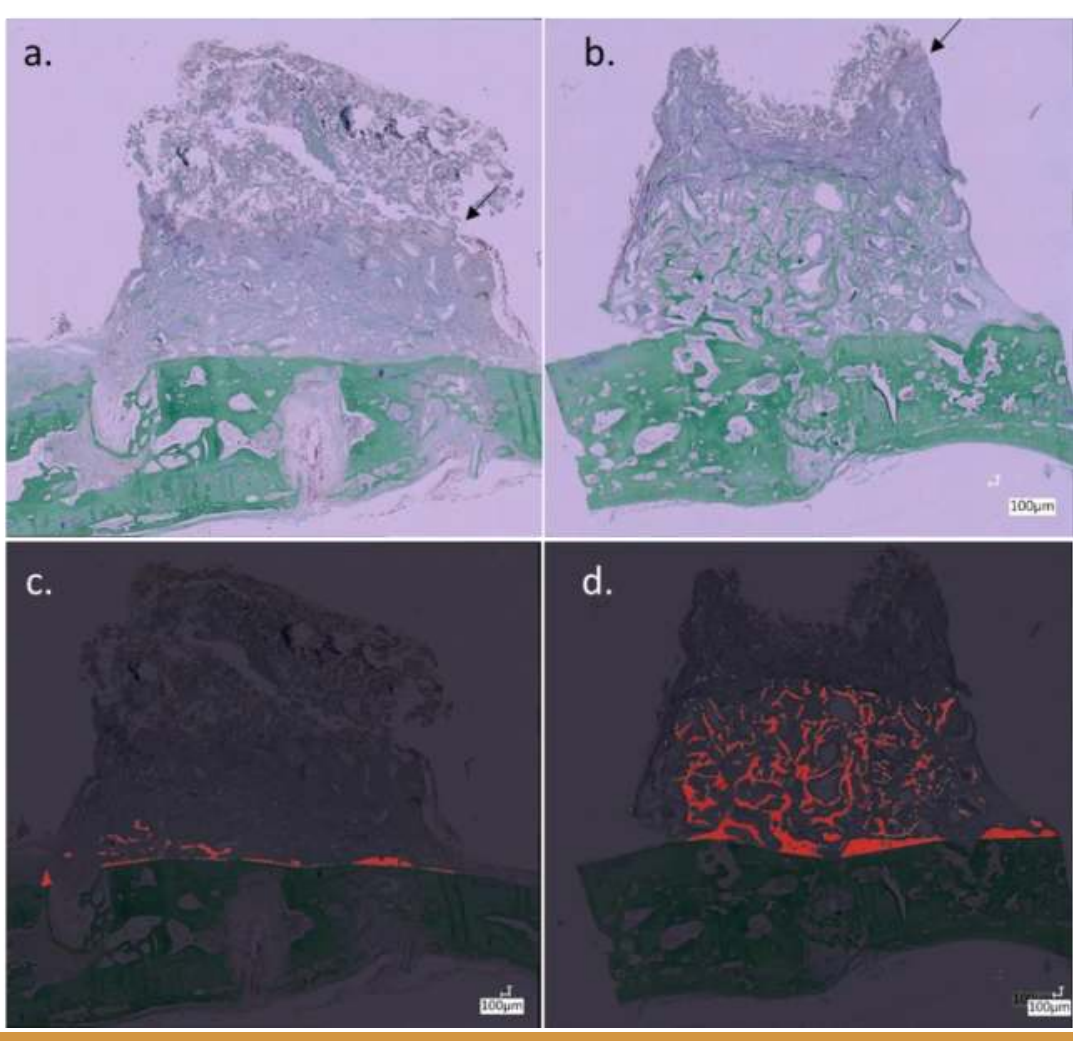

Background and Aim

\section{Results}

CD31-Endomucin In situ Hybridization (RNA view)

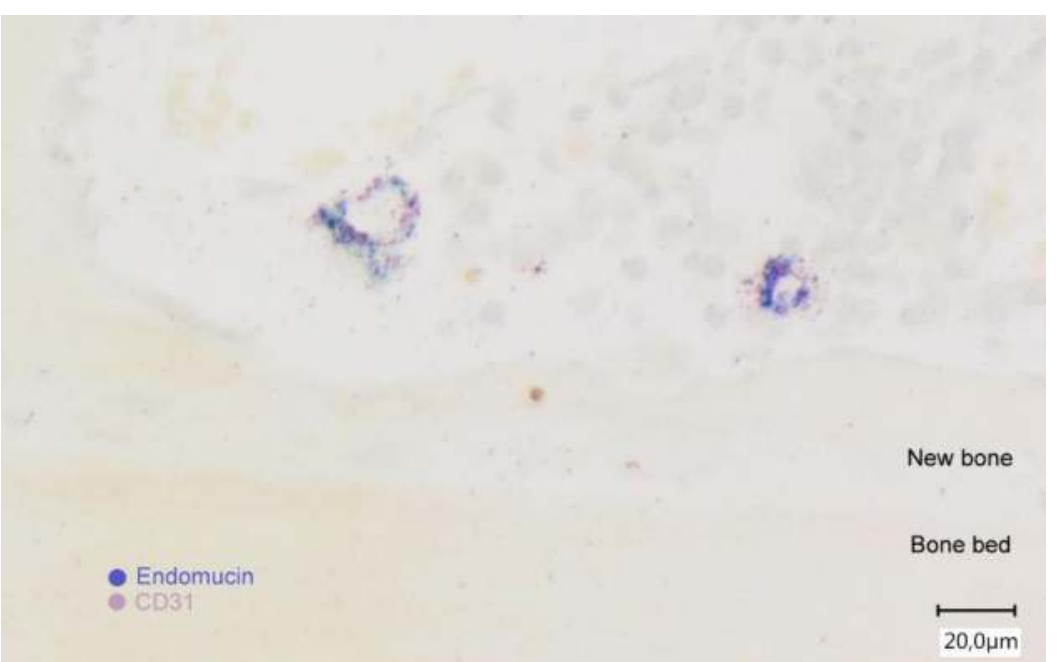

H-Endothelial cells Immunofluorescent staining (CD31-Edomucin at 2 weeks)

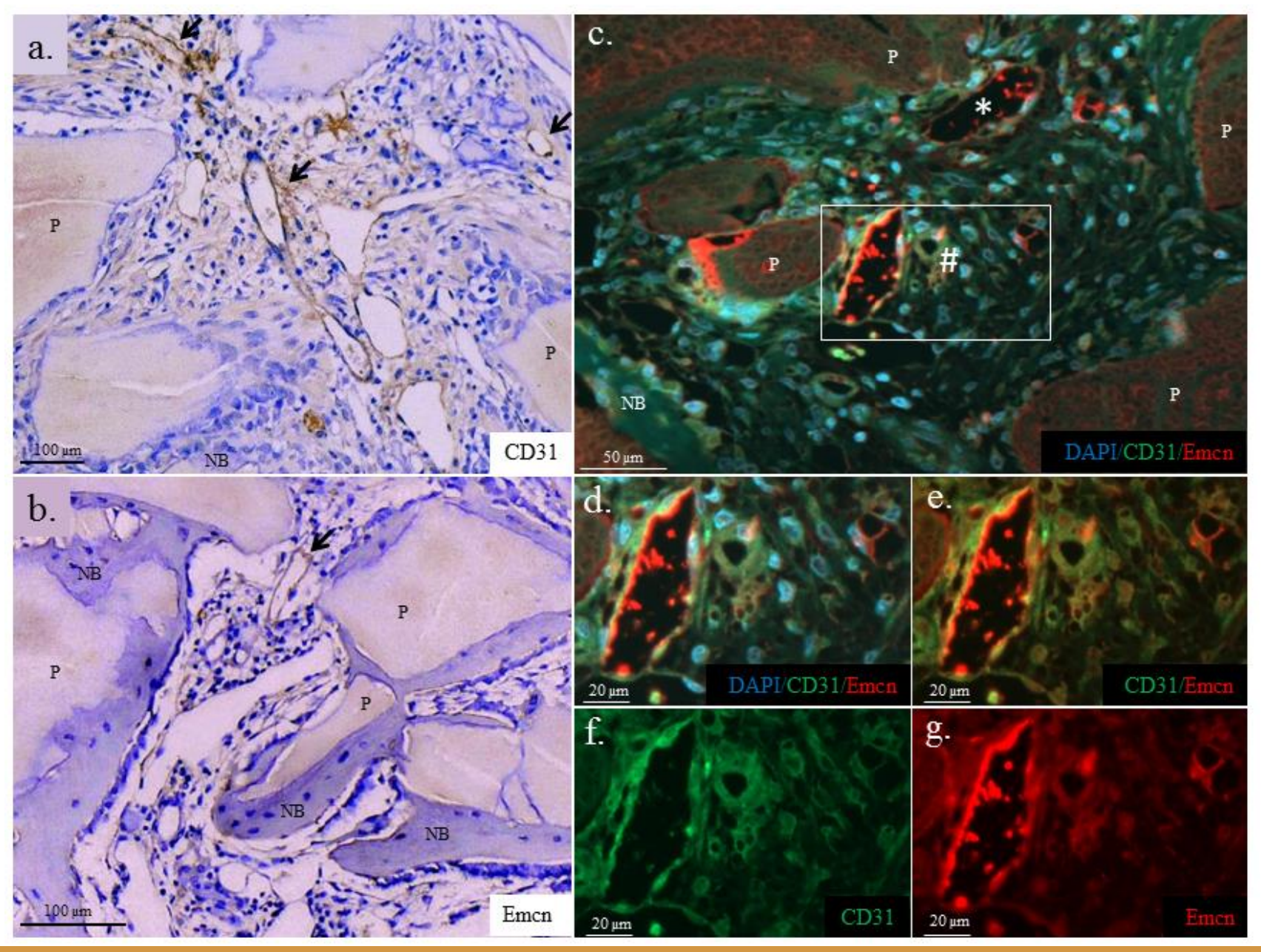

Conclusion
Endothelial cells (EC) are specialized with respect to a function and a local microenvironment. Recently, type-H EC $(\mathrm{H}-\mathrm{EC})$ were identified as the preferential interlocutor of osteoprogenitors (OP): H-EC promote osteogenesis and in return, OP promote angiogenesis. A clear correlation also exists between the concentration of OP and the presence of $\mathrm{H}-\mathrm{EC}$.

To date, nothing is known about the influence of bone substitute grafting on the recruitment of $\mathrm{H}-\mathrm{EC}$ to form these particular osteogenic niches.
These preliminary findings highly suggest the presence of type $\mathrm{H}$ endothelial cells in the neovascularized osteoid tissue grown thanks to the support of bone substitutes. Further detailed analysis are needed to assess the role and influence of these cells in the bone regeneration process. The influence of bone substitute composition on the recruitment of these particular cells may be also of prime importance.

\section{Methods and Materials}

The rabbit calvarial model for vertical bone augmentation was used: 4 PEEK cylinders were screwed onto rabbit skulls and filled with bone substitutes:

- Sham-blood clot (ctrl)

- Geistlich Bio-Oss ${ }^{\circledR}(\mathrm{GBO}$, ref pore size)

- Geistlich Bio-Oss ${ }^{\circledR}$ collagen (GBOC, ref pore size + additional extracellular matrix).

The mechanisms of bone regeneration were assessed with a focus on the recruitment of type $\mathrm{H}$ endothelial cells (H-EC). H-EC highly express CD31 and endomucin (EMCN).

Time lines: 3 days; $2 / 4$ wks

$\checkmark$ H-EC identification CD31-EMCN: Immunofluorescence, Immunohistology, in situ hybridization

$\checkmark$ Distance of the front of ossification: histomorphometry (Masson Goldner)

$\checkmark$ Amount of new bone tissue

\section{References}

Coupling of angiogenesis and osteogenesis by a specific vessel subtype in bone. Kusumbe et al. Nature 2014

Endothelial Notch activity promotes angiogenesis and osteogenesis in bone. Ramasamy et al. Nature 2014

Human type $H$ vessels are a sensitive biomarker of bone mass. Wang et al. Cell Death Dis 2017

\section{Acknowledgements}

Osteology foundation, Grant n¹8-049 